\title{
The Drug Metabolism and Pharmacokinetics Investigation about Baicalin Effect and Baicalein on Mice U14 Cervical Cancer
}

\author{
Zhanzhao Fu, ${ }^{1}$ Ya Di, ${ }^{1}$ Liming Gao, ${ }^{1}$ Jiandong Wu, ${ }^{1}$ Ming Shi, ${ }^{2}$ and Fulu Zheng ${ }^{1}$ \\ ${ }^{1}$ The First Hospital of Qinhuangdao, No. 258 Wenhua Road, Qinhuangdao 066004, China \\ ${ }^{2}$ Department of Biological Engineering, College of Environment \& Chemical Engineering, Yanshan University, \\ No. 438 Hebei Street, Qinhuangdao 066004, China \\ Correspondence should be addressed to Zhanzhao Fu; fuzhanzhaoyihao@163.com
}

Received 26 May 2014; Accepted 29 June 2014

Academic Editor: Tifeng Jiao

Copyright (C) 2015 Zhanzhao Fu et al. This is an open access article distributed under the Creative Commons Attribution License, which permits unrestricted use, distribution, and reproduction in any medium, provided the original work is properly cited.

\begin{abstract}
The experiment studies the effect of baicalin and baicalein on mice U14 cervical cancer and its pharmacokinetics in mice. By using different mouse models of cancer treatment program administered and uptake kinetics experiments, tissue distribution experiment, excretion, and metabolism in experimental experiments, we found that baicalin and baicalein can improve immunity and the ability of antioxidation and inhibit the growth of tumor. The absorption of intestinal drug takes place in intestinal tract. Tissue distribution was ideal. Because of the ideal drug distribution, the liver and kidney were protected. Drug was mainly excreted through the feces and bile excretion.
\end{abstract}

\section{Introduction}

Cervical cancer is one of the most worldwide serious malignant tumors that threat the lives of women. It ranks second in malignant tumor in the world [1]. In recent years, scientists explore the prevention, treatment, chance to reduce cervical cancer incidence, and mortality. Working though many years, scientists investigate some effective drugs, but it still needs a large number of experimental data as a powerful support.

Scutellaria baicalensis is the roots of Scutellaria baicalensis Georgi with the functions of clearing heat, detoxification, hemostasis, and tocolysis. Modern pharmacy studies prove that Scutellaria baicalensis root contains many kinds of flavonoids, including baicalin, baicalein, wogonoside, and wogonin which are the main effective components [2]. Baicalin and baicalein perform some pharmacological activities such as antioxidant, antiradiation, antibacterial, antiviral, antitumor [2, 3]. Some researches show that after glycoside bond of baicalin and wogonoside hydrolyzed, they will produce glucuronic acid and aglycones which can be absorbed in the stomach and intestine [4]. As a prodrug of baicalein, baicalin can be hydrolyzed by the intestinal flora enzymatic into the baicalein, which can be absorbed by the colonic epithelial cells. The absorbed baicalein was immediately reduced to baicalin, with blood circulation to the body organs and tissues; it produces some drug effect. Lots of experiments show that, due to the intestinal circulation, baicalin and baicalein perform a double-peaks phenomenon. At present, Scutellaria baicalensis preparations on the market mainly contain baicalin as the main component; the bioavailability is not ideal [5]. So, there is a need to explore the law of absorption of baicalin and baicalein and improve the efficacy of drugs.

In this experiment, baicalin and baicalein were discussed to explore the effects on U14 cervical cancer and its pharmacokinetics in U14 cervical cancer in mice. High performance liquid chromatography was used to detect relevant indicators [6] and provide data support for development and improvement of skullcap root.

\section{Experiments}

2.1. Materials. U14 cervical cancer cells taken from mice from the Chinese Academy of Medical Sciences Library of tumor cells in the level passage mice were intraperitoneally passing. Forty female Kunming mice were purchase at the Experimental Animal Center of Military Medical Sciences, Certificate of Conformity: 0023329. The body weight of 
each mouse was $22 \pm 5 \mathrm{~g}$, aging 3-6 weeks. Purchase at the Experimental Animal Center of Military Medical Sciences, Certificate of Conformity, was 0023329. Baicalin and baicalein were purchased from Chinese Herbal Medicine Company in Qinhuangdao City, Hebei Province; cyclophosphamide (CTX) was purchased from Shanxi Tai Sheng Pharmaceutical Co., Ltd., temporary NS formulated with saline to the required concentration $(25 \mathrm{mg} / \mathrm{kg})(25 \mathrm{mg} / \mathrm{kg})$; other chemical reagents were analytical grade.

2.2. U14 Cells of Mice Abdominal Cavity Passing and the Establishment of U14 Cervical Cancer in Mice Model. Two female mice were selected and disinfected and then the mice were injected into cervical cancer U14 cells [7, 8]. After 5 days, mice abdomen was markedly swollen, diet and activity decreased significantly, and mice ascites was collected. The ascites were centrifuged for $5 \mathrm{~min}$, the supernatant was removed, the added amount of $\mathrm{NaCl}$ solution was washed once, adding $\mathrm{NaCl}$ solution, adjustment cell concentration of $2 \times 10^{6} / \mathrm{mL}$. Subcutaneously injected U14 cells $0.2 \mathrm{~mL}$ into per mouse at the left fore alar $[6,7]$.

2.3. Research Methods of Antitumor Effect. The 40 tumorbearing mice were randomly divided into four groups of 10 $[9,10]$. According to the following scheme to drug treatment.

The first group: baicalin $(40 \mathrm{mg} / \mathrm{kg})$, lavage, 10 a tumor-burdened mouse, each $0.2 \mathrm{~mL}$.

The second group: radix scutellariae $(40 \mathrm{mg} / \mathrm{kg})$, lavage, 10 a tumor-burdened mouse, each $0.2 \mathrm{~mL}$.

The third group: cyclophosphamide $(25 \mathrm{mg} / \mathrm{kg})$, injected, 10 a tumor-burdened mouse, each $0.1 \mathrm{~mL}$.

The forth group: physiological saline, lavage, $10 \mathrm{a}$ tumor-burdened mouse, each $0.2 \mathrm{~mL}$.

All mice were administered 1 times/d, continuous administration for $15 \mathrm{~d}$, monitoring changes of tumor volume and weight. The 16th day, eyeball blood, then dissected mouse to collect tumor, thymus, spleen, and liver, weighed and make a record.

The calculation of inhibition rate [11] is as follows:

the tumor inhibition rate $=$ (tumor weight of the control group - tumor weight of the control group)/ tumor weight of the control group $\times 100 \%$.

Thymus index [11] is as follows:

thymus index $=$ thymus weight $(\mathrm{mg}) /$ body weight of mice $(\mathrm{g}) \times 10$.

The calculation of spleen index is as follows:

spleen index $=$ thymus weight $(\mathrm{mg}) /$ body weight of mice $(\mathrm{g}) \times 10$.

2.4. Absorption Kinetics Experiments. Take 18 tumor-bearing mice. A single oral administrate baicalin $(20 \mathrm{mg} / \mathrm{kg})+$ baicalein $(20 \mathrm{mg} / \mathrm{kg})$. Eyeball blood was added twice after administration for $7 \mathrm{~min}, 15 \mathrm{~min}, 30 \mathrm{~min}, 1 \mathrm{~h}, 2 \mathrm{~h}, 4 \mathrm{~h}, 8 \mathrm{~h}$, $16 \mathrm{~h}$, and $24 \mathrm{~h}$. The whole blood was added to the pretreated centrifuge centrifuged for $10 \mathrm{~min}$ [12]. Plasma $0.2 \mathrm{~mL}$ and methanol $1.5 \mathrm{~mL}$ were added into tube, $15 \mathrm{~min}$ centrifugation, and the supernatant was removed; add $20 \mu \mathrm{L} 0.1 \%$ phosphoric acid, after mixing, $0.45 \mu \mathrm{m}$ syringe filter with a filter to be analyzed. Remove heart, liver, spleen, lung, kidney, brain tissue, and $0.5 \mathrm{~g}$ tissue and add $0.5 \mathrm{~mL}$ saline, homogenized. The homogenate was set in centrifuged tube, $0.4 \mathrm{~mL}$ of methanol was added, vortex $10 \mathrm{~min}$, and centrifuged for $15 \mathrm{~min}$; the supernatant was added $20 \mu \mathrm{L} 0.1 \%$ phosphoric acid, using $0.45 \mu \mathrm{m}$ syringe filter to filter the solution.

2.5. Excretion Experiment. The experiment was divided into treatment group and control group, $n=10$ tumor-bearing mice, which were placed in a metabolic cage rearing. Mice were fasted for $12 \mathrm{~h}$, but water was allowed. $12 \mathrm{~h}$ later, a single oral administrate baicalin $(20 \mathrm{mg} / \mathrm{kg})+$ baicalein $(20 \mathrm{mg} / \mathrm{kg})$. After the control group was administered $0-4 \mathrm{~h}, 4-8 \mathrm{~h}, 8-$ $12 \mathrm{~h}$, and $12-24 \mathrm{~h}$, all urine and feces were collected [13]. According to the above processing method, handle the sample processing. Take four tumor-bearing mice, a single oral administrated baicalin $(20 \mathrm{mg} / \mathrm{kg})+$ baicalein $(20 \mathrm{mg} / \mathrm{kg})$, taking bile. According to the above processing method handle the sample processing.

2.6. Metabolic Experiments. A single oral administration in 4 mice, took bile $4 \mathrm{~h}$ later, methanol was added to a final volume of $1 \mathrm{~mL}$, using $0.45 \mathrm{um}$ syringe filter to filter, injection analysis.

\subsection{Determination of HPLC}

Column [12, 14]: Agilent Eclipse XDB-C18 (250 mm $\times$ $4.6 \mathrm{~mm}, 5 \mu \mathrm{m})$;

mobile phase: methanol (A) $-0.1 \%$ phosphoric acid solution (B), 40\% A (0 min), 80\% A (40 min), 40\% A $(60 \mathrm{~min})$, detection wavelength of $277 \mathrm{~nm}$, a flow rate of $1.0 \mathrm{~mL} / \mathrm{min}$;

analysis voltage: $100 \mathrm{mV}$;

protection voltage: $500 \mathrm{mV}$;

column temperature: $30^{\circ} \mathrm{C}$;

injection volume: $20.0 \mu \mathrm{L}$;

number of theoretical plates of not less than 10,000;

preparation of the reference solution: precision weight baicalin, baicalein reference $5 \mathrm{mg}$ and $5 \mathrm{mg}$, in the same $50 \mathrm{~mL}$ volumetric flask; add methanol amount of ultrasound to dissolve, diluted to the mark with methanol.

2.8. Statistical Data Processing Method. Experimental data are presented as mean \pm standard deviation $( \pm S)$, each set of data was collected using the $t$ test. 
TABLE 1: The effect of baicalin and baicalein inhibition rate of U14 cervical cancer in mice.

\begin{tabular}{lcc}
\hline Groups & $\begin{array}{c}\text { The average tumor } \\
\text { weight }(\mathrm{g})\end{array}$ & Inhibition rate (\%) \\
\hline Negative & $2.29 \pm 0.42$ & - \\
Positive & $1.47 \pm 0.11$ & 35.81 \\
Baicalin & $1.06 \pm 0.03$ & 53.71 \\
Scutellarein & $1.40 \pm 0.28$ & 38.86 \\
\hline
\end{tabular}

\section{Results}

3.1. Established Mouse Model of Cancer U14. 5d tumors in mice after planting, armpit lump visible success rate of $100 \%$ was observed before and after the state of motion modeling in mice and found that mice before modeling activities between eating large; After modeling, reduced activity, food intake, less water than before modeling, created by the above phenomenon known U14 cancer mouse model is successful.

3.2. Baicalin and Baicalein Chinese Anticancer Effects in Mice U14. Compared with the positive control group, baicalin and baicalein tumor inhibition rates were higher than the positive control group, but the difference was not statistically significant. And the size of the relationship between the inhibition rate was baicalin > baicalein; the results are shown in Table 1.

Comparing Thymus Index. Compared with the positive control group, baicalin and baicalein group were significantly higher than the positive control group $(P<0.01)$; compared with the negative control group, baicalin group was significantly higher than the negative control group $(P<0.01)$.

Comparing Spleen Index. Compared with the positive control group, baicalein and baicalin group were significantly higher than the positive control group $(P<0.01)$; compared with the negative control group, baicalein group was higher than the negative control group $(P<0.05)$.

Due to cyclophosphamide lack of targeting, it not only can effectively suppress tumors but also reduces the immune organism. Thymus and spleen are the two organisms immune organ, on behalf of the immunity organisms [15]. So thymus index and spleen index positive control group were lower than the experimental group and control group. Negative control group of mice completely inhibits tumor immunity on its own, so the thymus and spleen compared with normal mice developed; the results are shown in Table 2.

3.3. Blood Standard Curve Test. Baicalin was accurately weighed, baicalein reference was $31.89 \mathrm{mg}$ and $10.62 \mathrm{mg}$, in the same $50 \mathrm{~mL}$ volumetric flask; add amount of methanol ultrasound to dissolve. The reference concentration of baicalin was diluted from $637.80 \mathrm{ug} / \mathrm{mL}$ times to $31.890 \mathrm{ug} / \mathrm{mL}$; scutellarein concentration was diluted from $212.4 \mathrm{ug} / \mathrm{mL}$ fold to $10.62 \mathrm{ug} / \mathrm{mL}[6,16,17]$.

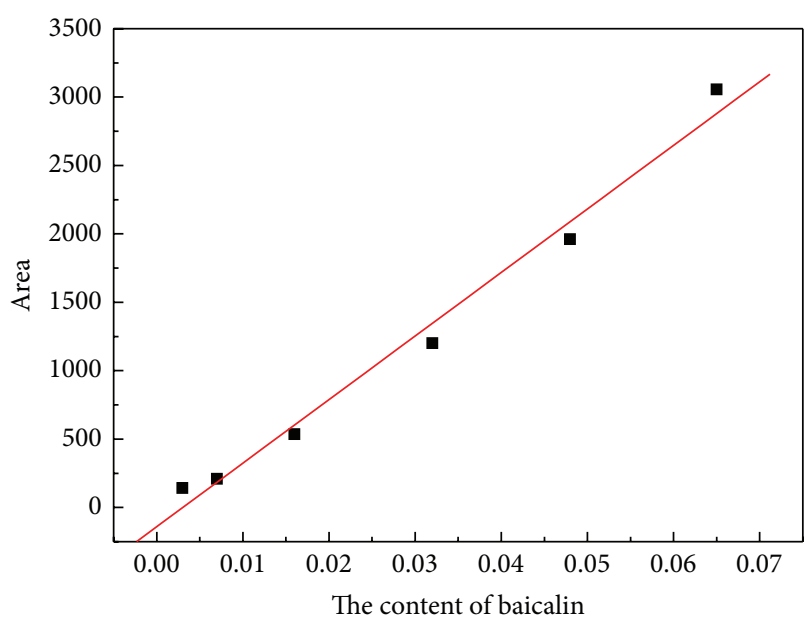

FIgURE 1: Baicalin standard curve.

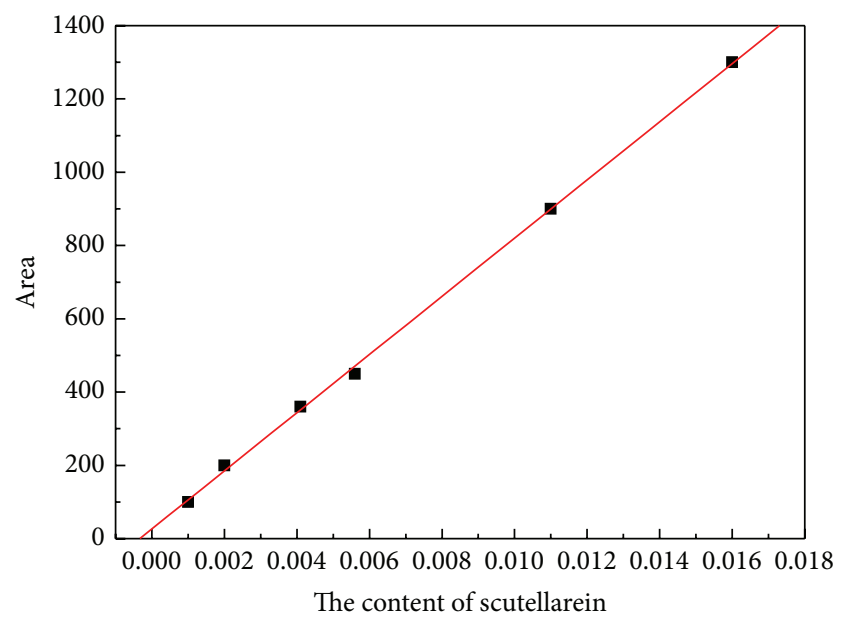

FIGURE 2: Scutellarein standard curve.

Experiments baicalin $\left(x_{1}, \mathrm{ug} / \mathrm{mL}\right)$ and the peak area $\left(y_{1}\right)$ in the relation: $y_{1}=m_{1} x_{1}+b_{1}$, where $m_{1}=46869.17$ and $b_{1}=-108.19$, are shown in Figure 1 .

Baicalein content $\left(x_{2}, \mathrm{ug} / \mathrm{mL}\right)$ and the peak area $\left(y_{2}\right)$ in the relationship: $y_{2}=m_{2} x_{2}+b_{2}$, where $m_{2}=84244.97$ and $b_{2}=4.57$, are shown in Figure 2 .

3.4. Organizations Like the Standard Curve. In the experiment, baicalin was accurately weighed and baicalein reference was $5 \mathrm{mg}$ and $5 \mathrm{mg}$, in the same $50 \mathrm{~mL}$ volumetric flask; add amount of methanol ultrasound to dissolve. A concentration of $100 \mathrm{ug} / \mathrm{mL}$ standard solution using the method of dilution magnification was diluted to $3.125 \mathrm{ug} / \mathrm{mL}$ 5 injections gradient $[9,14,18]$, the standard curve (Figures 3 and 4).

Experiments baicalin $\left(x_{3}, \mathrm{ug} / \mathrm{mL}\right)$ and the peak area $\left(y_{3}\right)$ are in relation to $y_{3}=m_{3} x_{3}+b_{3}$, where $m_{3}=5.99$ and $b_{3}=$ -0.59 . 
TABLE 2: The effect of baicalin and baicalein on U14 cervical thymus index and spleen index.

\begin{tabular}{|c|c|c|c|c|c|}
\hline Groups & $\begin{array}{l}\text { Body weight } \\
\text { (g) }\end{array}$ & $\begin{array}{l}\text { The average weight of } \\
\text { the thymus (mg) }\end{array}$ & $\begin{array}{l}\text { The average spleen } \\
\text { weight }(\mathrm{mg})\end{array}$ & $\begin{array}{l}\text { Thymus } \\
\text { index }\end{array}$ & Spleen index \\
\hline Negative & $34.51 \pm 0.99$ & $82.05 \pm 20.94$ & $425.03 \pm 46.76$ & 23.78 & 123.16 \\
\hline Positive & $30.12 \pm 0.94$ & $44.31 \pm 18.99$ & $249.52 \pm 80.58$ & $14.71^{\wedge}$ & 82.84 \\
\hline Baicalin & $28.03 \pm 0.85$ & $121.21 \pm 16.18$ & $357.63 \pm 17.89$ & $43.24^{* * \wedge \wedge}$ & $127.59^{* *}$ \\
\hline Scutellarein & $34.46 \pm 2.34$ & $95.03 \pm 13.89$ & $492.04 \pm 65.81$ & $27.58^{* *}$ & $142.79^{* * \wedge}$ \\
\hline
\end{tabular}

The positive control group: ${ }^{*} P<0.05,{ }^{* *} P<0.01$, with the negative control group: ${ }^{\wedge} P<0.05,{ }^{\wedge} P<0.05$.

TABLE 3: Blood concentrations of baicalin-schedule.

\begin{tabular}{lc}
\hline Sampling time point & Concentration of baicalin $(\mathrm{ng} / \mathrm{mL})$ \\
\hline $7^{\prime}$ & 937.47 \\
$15^{\prime}$ & 739.35 \\
$30^{\prime}$ & 914.28 \\
$1 \mathrm{~h}$ & 892.17 \\
$2 \mathrm{~h}$ & 906.81 \\
$4 \mathrm{~h}$ & 915.87 \\
$8 \mathrm{~h}$ & 748.83 \\
$16 \mathrm{~h}$ & 924.27 \\
$24 \mathrm{~h}$ & 945.99 \\
\hline
\end{tabular}

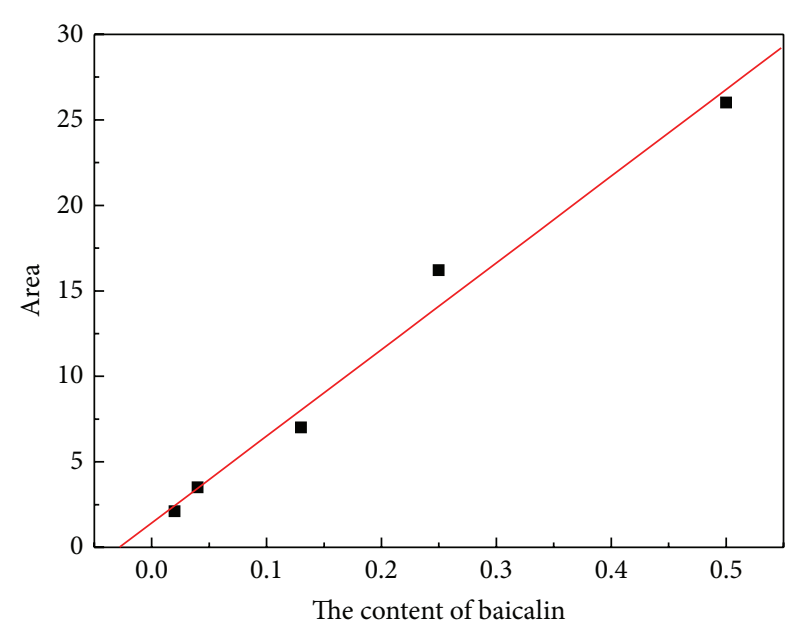

Figure 3: Baicalin standard curve.

Scutellarein content $\left(x_{4}, \mathrm{ug} / \mathrm{mL}\right)$ and the peak area $\left(y_{4}\right)$ are in relation to $y_{4}=m_{4} x_{4}+b_{4}$, where $m_{4}=49.22$ and $b_{4}=-22.81$.

3.5. Absorption Kinetics Experiments. Blood samples at all time points only detected baicalin absorption peak (peak 1) (Note: Peak 1 baicalin), not scutellarein absorption peaks, as shown in Figure 2. And the baicalin concentration of plasma appears first plateau after administration for $0.5 \mathrm{~h} \sim 4 \mathrm{~h}$ and $16 \mathrm{~h} 24 \mathrm{~h}$ being a second plateau. This is because scutellarein ester-soluble glycosides are better; only baicalin turns into scutellarein; it can be absorbed by the intestinal epithelial cells. Baicalin is absorbed into the blood quickly and converts into scutellarein, so no scutellarein was detected in blood

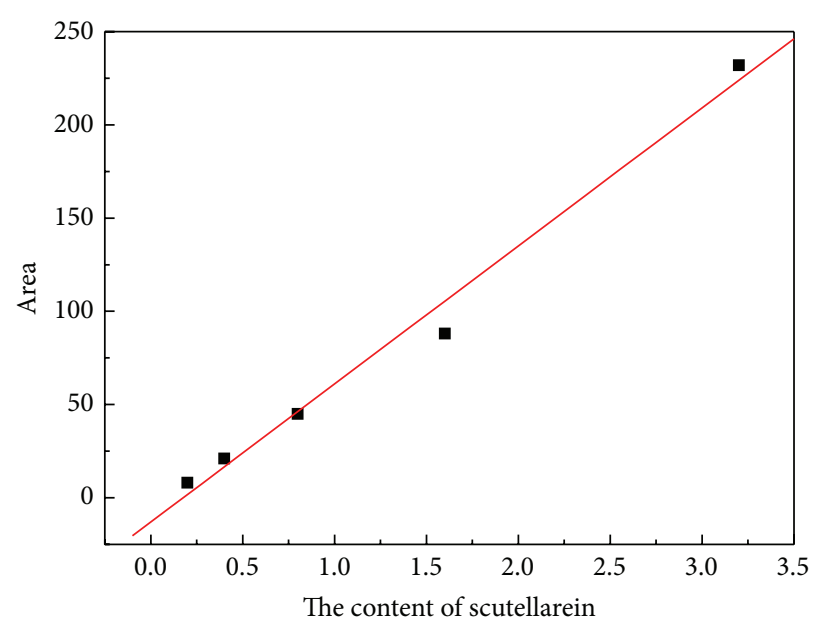

FIGURE 4: Scutellarein standard curve.

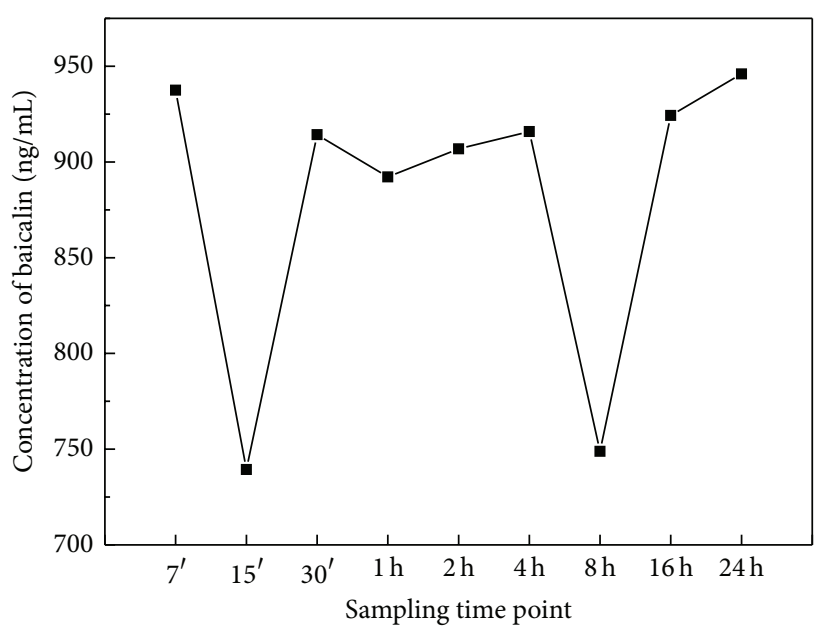

FIGURE 5: Baicalin blood concentrations versus time diagram.

samples. And the presence of baicalin intestinal absorption cycle that is absorbed into the blood baicalin reverted into scutellarein again into the intestine, to be absorbed by the next time, so there will be two absorption plateaus, as shown in Table 3 and Figure 5.

3.6. Excretion Experiment. Baicalin and baicalein absorption peak was not detected in urine samples. In faeces, the content of baicalin is higher than the content of baicalein, and 
TABLE 4: Feces baicalin and baicalein content (ug/g feces).

\begin{tabular}{lcccc}
\hline & $0-4 \mathrm{~h}$ & $4-8 \mathrm{~h}$ & $8-12 \mathrm{~h}$ & $12-24 \mathrm{~h}$ \\
\hline Baicalin & 45.04 & 90.98 & 45.10 & 51.78 \\
Scutellarein & 18.59 & 39.49 & 22.01 & 55.59 \\
\hline
\end{tabular}

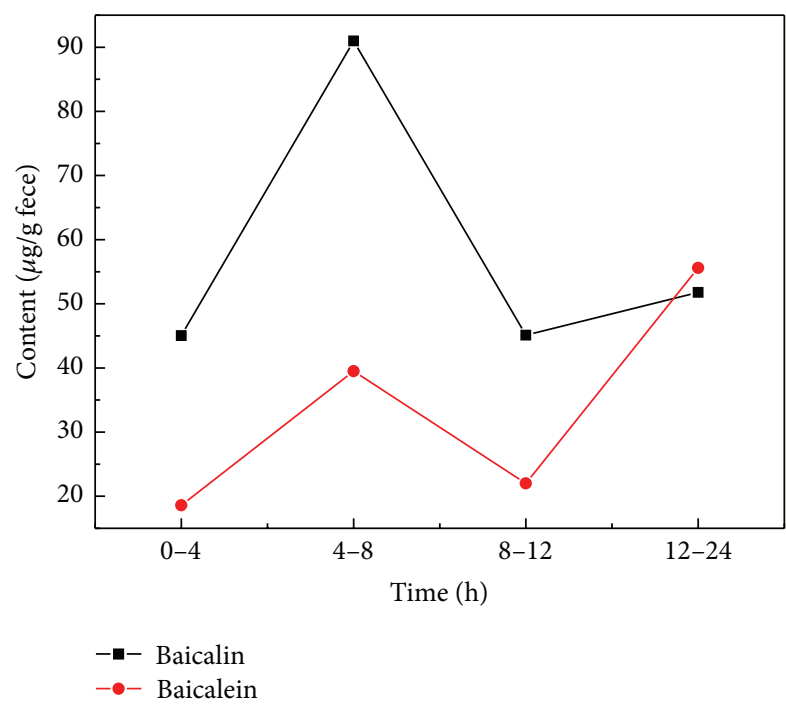

FIGURE 6: Baicalin and baicalein content at each time phase diagram in fecal content.

the content of baicalin and baicalein in feces are a double absorption peak. This is because baicalein is with a wide range of absorption in the gastrointestinal absorption system, and baicalin can only in the colonic bacteria secrete enzymes, into baicalein, without the enzyme action large number of baicalin out of body with feces [15]. So feces of mice have higher levels of baicalin. Double absorption peak is also due to the presence of intestinal loop sake. Data are shown in Table 4 and Figures 6 and 7.

3.7. Metabolic Experiments. Samples measured baicalin absorption peak area of $56.12 \mathrm{mAU} * \mathrm{~S}$ and scutellarein absorption peak area of $2.99 \mathrm{mAU} * \mathrm{~S}$ by HPLC. According to the standard curve formula, baicalin was $2.37 \times 10^{-1} \mathrm{mg} / \mathrm{mL}$ and scutellarein content was $1.31 \times 10^{-2} \mathrm{mg} / \mathrm{mL}$. HPLC chromatographic result is shown in Figure 8.

3.8. Tissue Distribution Experiments. Just as blood samples, tissue samples can only detect baicalin absorption peak (1) but could not detect scutellarein absorption peaks as shown in Figures 3-10. After baicalin and baicalein medicine gavage $4 \mathrm{~h}$, the content of baicalin in each tissue is heart > lung > cancer $>$ kidney $>$ liver. Since gavage $4 \mathrm{~h}$, baicalin plasma concentration reached a plateau for the first time, so the drug concentration is the highest in the organization. Baicalin combined with biological heart and lung tissue easily, so the tissue drug concentrations are high. In tumor tissue, baicalin content is higher than that in kidneys and liver, indicating a high using degree of baicalin and baicalein medicine. Baicalin accumulated more in tumor tissue and took its role; excess

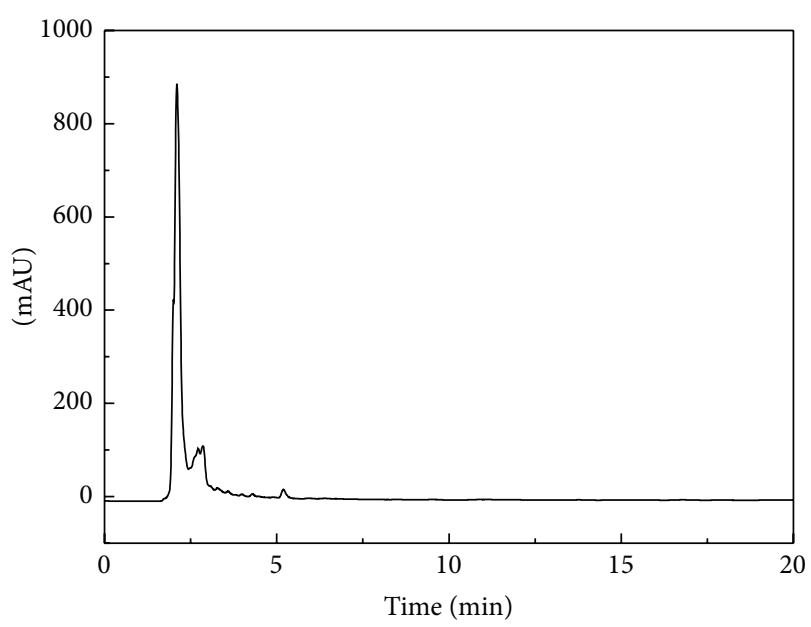

FIgURE 7: Test group and control group comparison chart fecal homogenates chromatography.

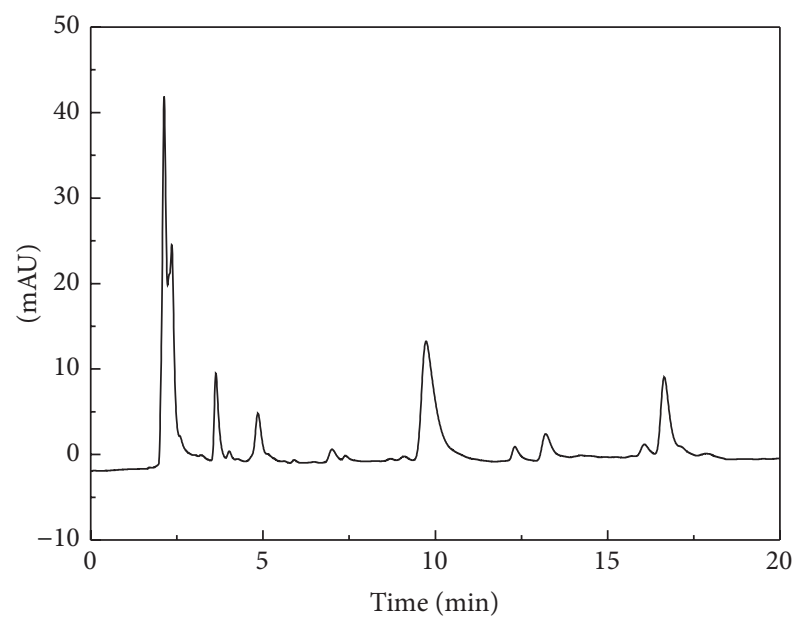

FIGURE 8: HPLC chromatogram of bile.

baicalin through the liver and kidneys and other metabolites organs were excreted out of body; the results were shown in Table 5 and Figures 9 and 10.

\section{Discussions}

Baicalin and baicalein belong to polyphenolic compounds with weak acid; therefore, baicalin and baicalein which is the state of the molecule in the stomach may be easier to be absorbed through the mucosa. Rat gastric absorption test results showed that baicalin and baicalein are absorbed in the stomach, in which baicalein showed good absorption characteristics. The extent of absorption is far superior baicalin [14], which may be due to the removal of glycosylated aglycone baicalein having more fat-soluble and hydrophobic. Thus it is easier to pass through the gastric mucosa.

The liver is the major site of most drug metabolisms. Most flavonoids metabolism occurs in the digestive tract and liver. Baicalin metabolites in rat liver were baicalein 
TABLE 5: U14 cervical cancer organizations mice baicalin.

\begin{tabular}{lccccccc}
\hline Organization & Heart & Liver & Spleen & Lung & Kidney & Brain & Tumor \\
\hline Content & 3.708 & 1.104 & 0 & 3.029 & 1.334 & 0 & 1.690 \\
\hline
\end{tabular}

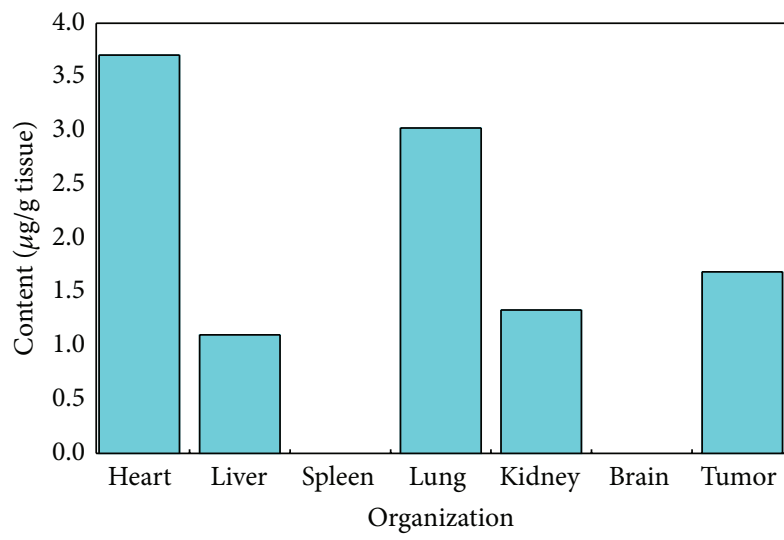

FIGURE 9: Baicalin content in each group.

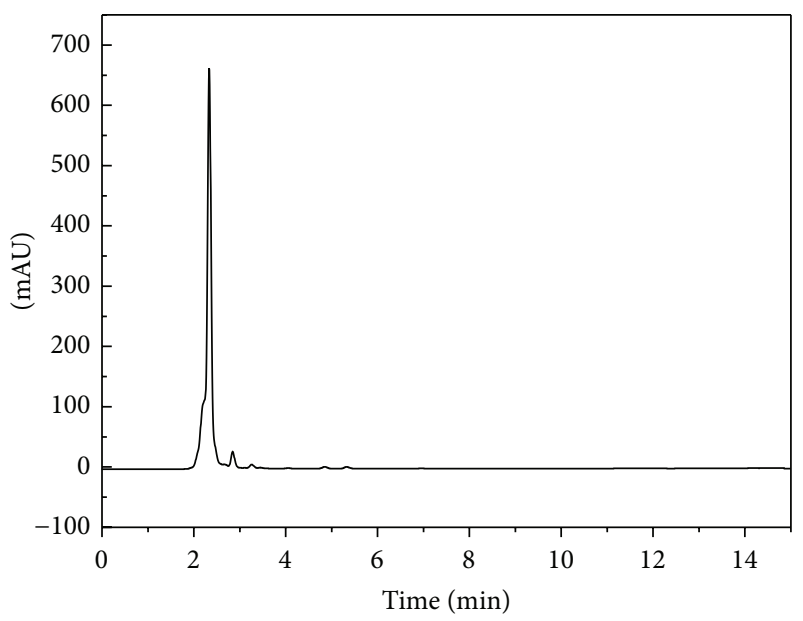

FIGURE 10: HPLC of lung homogenate.

6-O- $\beta$-glucuronide (M1), 6-O-methyl-baicalein 7-O- $\beta$-glucuronide (M2), baicalein 7-O- $\beta$-glucuronide (M3), 6-O$\beta$-glucuronidase-baicalein-7-O-sulfate (M4), and baicalein 6,7 -di-O- $\beta$-glucuronide (MS), in which five metabolites, including M4 and M5, of polar metabolites are relatively high; a relatively large molecular weight is the major. Some traditional Chinese herbal formula changes will lead directly baicalin metabolites in the liver changes. Baicalin or baicalein metabolites way in urine mainly combines methylation and glucuronide. Baicalin exhibits enterohepatic circulation, after intravenous administration of baicalin solution, with its prototype and metabolites meter; enterohepatic circulation percentages were $4.8 \%$ and $13.3 \%$. After oral administration of baicalin solution, with its prototype and metabolites meter, enterohepatic circulation percentage was $18.7 \%$ and $19.3 \%$.

\section{Conclusions}

Through the study of baicalin and baicalein absorption kinetics experiment, tissue distribution, excretion, and metabolism test, we can draw the following conclusions. The active pharmaceutical ingredient mainly exists in the form of baicalin in blood, which reached the highest concentration in $0.5 \sim 4 \mathrm{~h}$ and $12 \sim 24 \mathrm{~h}$. This indicated that the baicalin is absorbed through the gastrointestinal circulation. Four hours later after gavage, the content of baicalin in tumor, heart, liver, and kidney reached a higher concentration. Baicalin and baicalein are mainly excreted through the fecal excretion and bile excretion. In this experiment, baicalin and baicalein, as an anticancer drug, and the two effects on U14 cervical cancer and the pharmacokinetic process in mice were discussed. It provided a data support for the development and improvement of Scutellaria baicalensis.

\section{Conflict of Interests}

The authors declare that they have no any direct financial relation with the commercial identities mentioned in this paper that might lead to a conflict of interests for any of the authors.

\section{References}

[1] L. D. Yuan, H. Xu, and Z. Du, "Influence of Baicalin on Ehrlich ascites carcinoma cell: a preliminary study," Journal of Nanjing Railway Medical College, vol. 16, no. 4, pp. 231-233, 1997.

[2] R. Liang, C. Chen, X. Yi et al., "Structural origins of the differential antioxidative activities between baicalein and Baicalin," OALib Journal, vol. 27, no. 1, pp. 132-140, 2010.

[3] L. X. Yang, D. Liu, X. F. Feng et al., "Determination of flavone for Scutellaria baicalensis from different areas by HPLC," Zhongguo Zhong Yao Za Zhi, vol. 27, no. 3, pp. 166-170, 2002.

[4] H. Shi, B. Zhao, and W. Xin, "Scavenging effects of Baicalin on free radicals and its protection on erythrocyte membrane from free radical injury," Biochemistry and Molecular Biology International, vol. 35, no. 5, pp. 981-994, 1995.

[5] R. Su, X. Lin, and X. Zhuang, "Scutellarein study protective effects of hydrogen peroxide-induced injury in PC12 cells," Pharmaceutical Journal, vol. 35, no. 3, pp. 161-165, 2005.

[6] N. Su, R. Luo, H. Su et al., "Effect of Baicalin on renal function in diabetic nephropathy rats and its anti-oxidative action," Traditional Chinese Drug Research \& Clinical Pharmacology, vol. 18, no. 5, p. 341, 2007.

[7] Y. Fang, D. Hu, and X. Li, "Baicalin and copper (II), scavenging zinc (II) complexes of superoxide radicals," Xian Medical University, vol. 18, no. 1, p. 41, 1997.

[8] F. Yin, Y. Yang, and P. Yu, "Changes of glutamate and gammaaminobutyric acid contents in brain tissue of brain edema and effects of Baicalin on them in rats," Zhongguo Zhong Xi Yi Jie He Za Zhi, vol. 20, no. 7, pp. 524-526, 2000. 
[9] Y. Hou, X. Zhu, and G. Cheng, "Study on the anti-inflammatory mechanism of Baicalin," Yaoxue Xuebao, vol. 35, no. 3, pp. 161$164,2000$.

[10] A. S. Pannala, T. S. Chan, P. J. O’Brien, and C. A. RiceEvans, "Flavonoid B-ring chemistry and antioxidant activity: fast reaction kinetics," Biochemical and Biophysical Research Communications, vol. 282, no. 5, pp. 1161-1168, 2001.

[11] C. Cheng, N. Feng, Q. Tang et al., "Baicalin on common eye original in vitro antibacterial effect," Chinese Journal of Hospital Pharmacy, vol. 21, no. 6, p. 384, 2001.

[12] M. Gong, L. Yu, Q. Chen et al., "Gavage Baicalin its aglycone baicalein pharmacokinetic study," Herbal, vol. 40, no. 3, 2009.

[13] X.-B. Guan, L. Ye, B.-J. Xia, and Z.-Q. Liu, "Effects of various microsomal drug-metabolizing enzymes on specific glucuronidation of baicalein in rats'liver and intestine," Chinese Journal of Cerebrovascular Diseases, vol. 19, no. 36, pp. 2811-2813, 2008.

[14] M.-Y. Lai, S.-L. Hsiu, C.-C. Chen, Y.-C. Hou, and P.-D. L. Chao, "Urinary pharmacokinetics of baicalein, wogonin and their glycosides after oral administration of scutellariae radix in humans," Biological and Pharmaceutical Bulletin, vol. 26, no. 1, pp. 79-83, 2003.

[15] J. Xing, X. Chen, and D. Zhong, "Absorption and enterohepatic circulation of Baicalin in rats," Life Sciences, vol. 78, no. 2, pp. 140-146, 2005.

[16] Q. Lan, K. Chu, S. Qiu, and X. Shen, "Experimental 23 study on stability of compound scutellaria solution," China Pharmaceutical University, vol. 20, no. 2, pp. 106-108, 1989.

[17] Q. Wang, "HPLC method for the determination ofBaicalin skullcap of," Herbal, vol. 20, no. 8, pp. 15-16, 1989.

[18] Y. Zhou and J. Ni, "Determination of baicalin content in Children's lung cleaning oral liquid by HPLC," Medicine, vol. 15, no. 1, p. 16, 1993. 

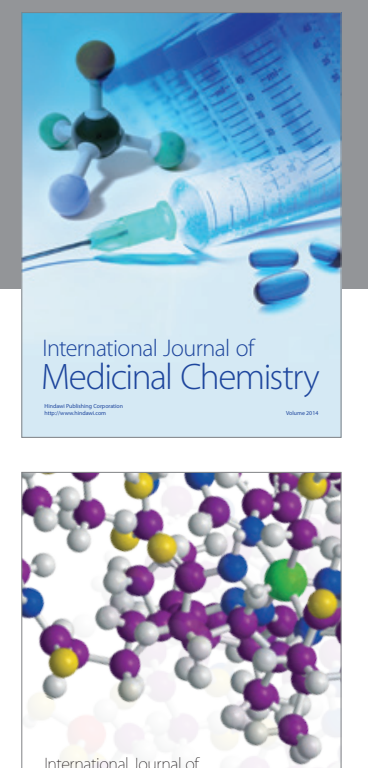

\section{Carbohydrate} Chemistry

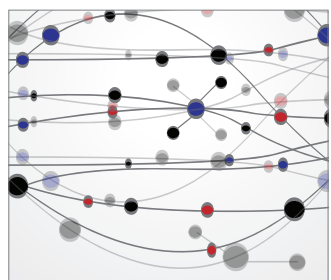

The Scientific World Journal
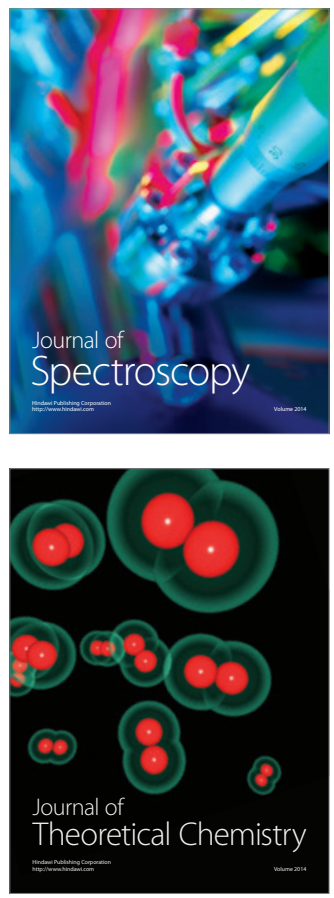
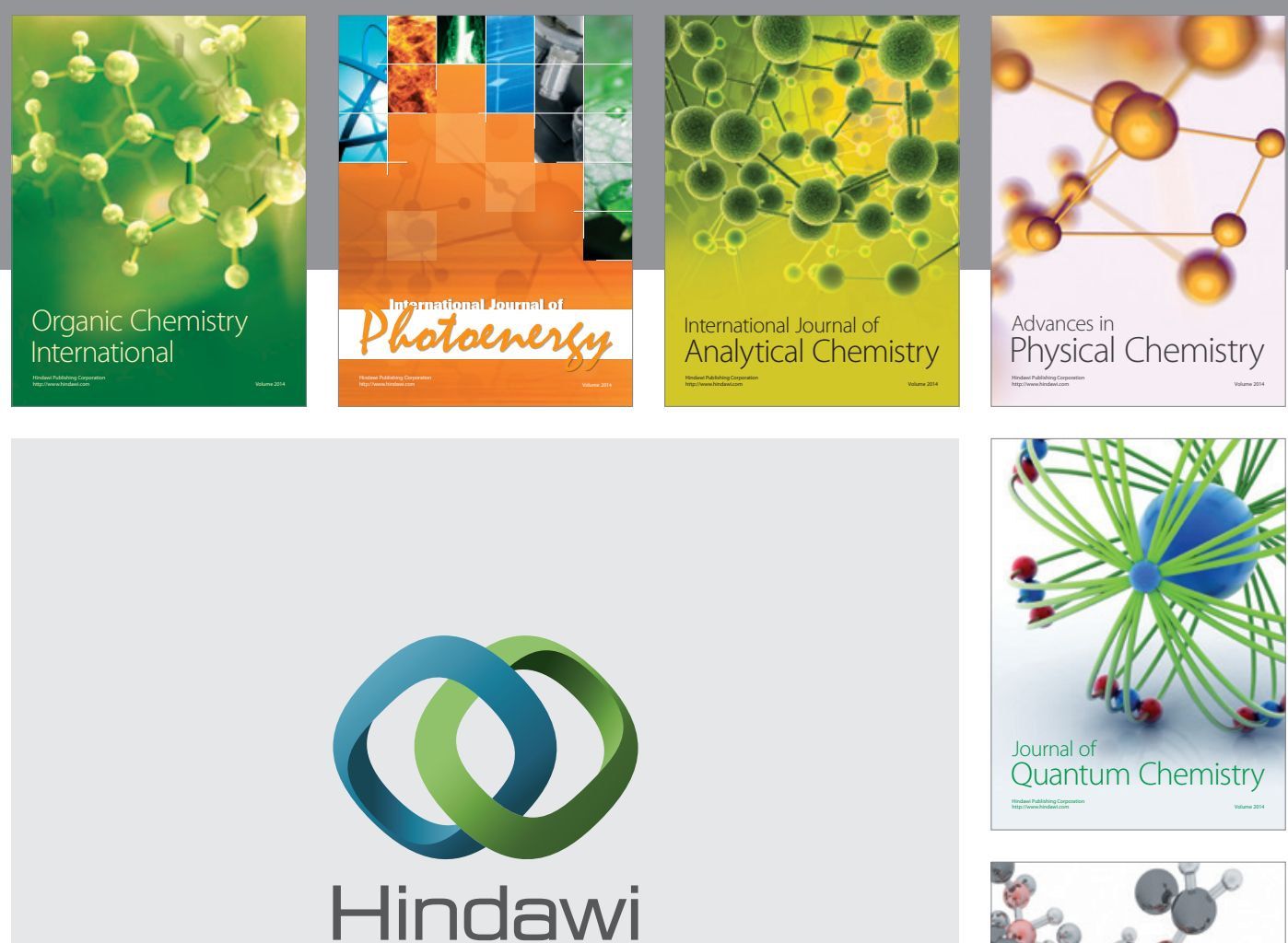

Submit your manuscripts at

http://www.hindawi.com

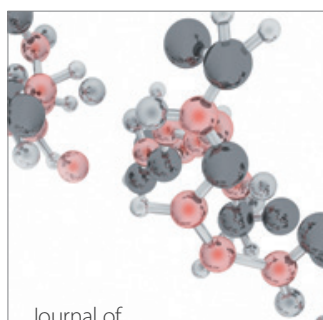

Analytical Methods

in Chemistry

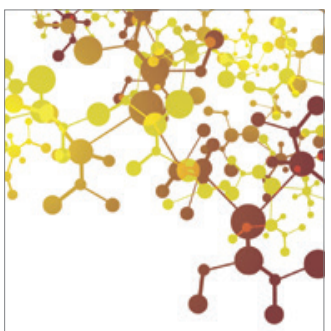

Journal of

Applied Chemistry

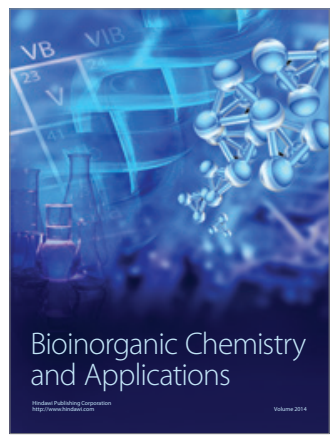

Inorganic Chemistry
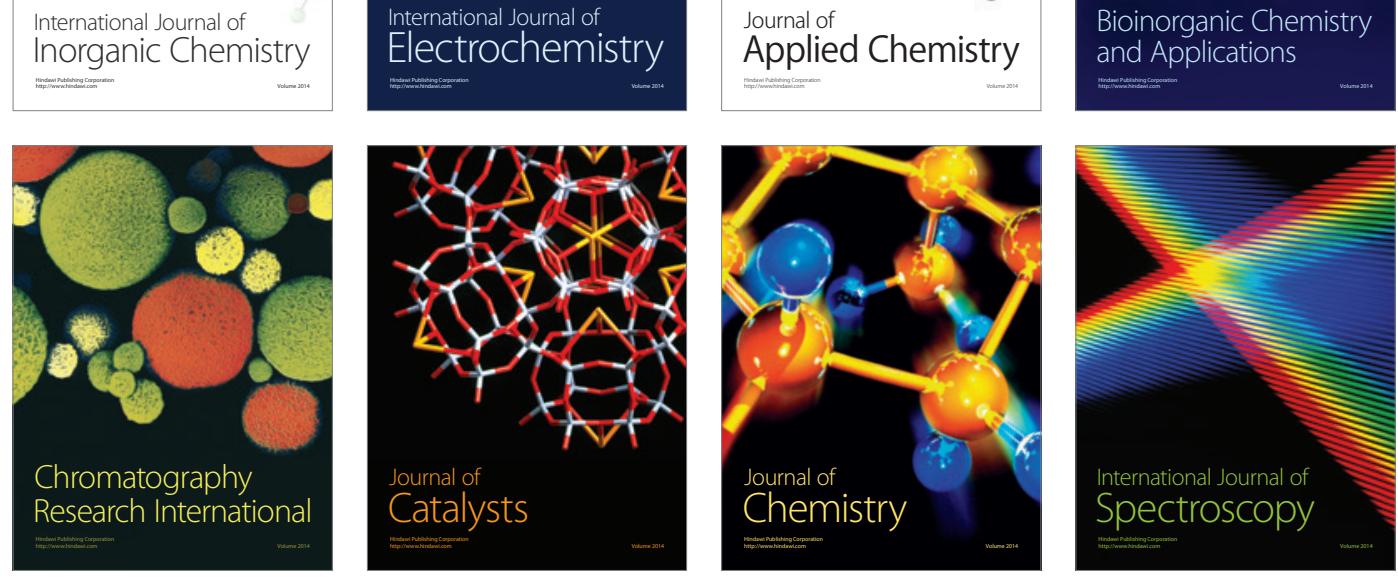